\title{
Comparing safety and efficiency of two closed-chamber techniques for iridodialysis repair - a retrospective clinical study
}

\author{
Wenjuan Wan', Lei Shi ${ }^{2}$ and Can $\mathrm{Li}^{i^{*}}$
}

\begin{abstract}
Background: This study aims to compare the safety and effectiveness of two closed-chamber techniques for repairing iridodialysis.

Methods: Seventy five patients with iridodialysis undergoing surgery from February 2008 to October 2017 were included in this study. Patients were divided into two Groups, Group A (32 eyes) and Group B (35 eyes), with Group A using a 26-gauge hypodermic needle guided 10-0 nylon suture, and Group B using a double-armed polypropylene suture. Before operation and 1, 3, and 6 months after the operation, pupil shape, best corrected visual acuity (BCVA), intraocular pressure (IOP), the rate of endothelial cell loss, and intra- and postoperative complications were compared between two Groups during the follow-up period.

Results: Iridodialysis was repaired with pupil shape restored in all cases. IOP was normalized in all eyes except 2 eyes (6.3\%) in Group A and 3 eyes (8.6\%) in Group B. Postoperative rate of endothelial cell loss was not significantly different between two Groups $(P>0.05)$. The percentage of complicated cataract was not significantly different in Group A (2 eyes, 6.3\%) compared to Group B (2 eyes, 5.7\%) $(x 2=0.009, P=0.658)$.

Conclusions: Both techniques for repairing iridodialysis not only were safe but also effective in improving visual function and cosmetic recovery. However, double-armed polypropylene suture might be less invasive than 26-gauge hypodermic needle guided suture.
\end{abstract}

Keywords: Iridodialysis, Iridoplasty, Closed-chamber technique, Iridodialysis repair, Iris tear

\section{Background}

Iridodialysis is a separation of the iris from its attachment to the ciliary body. It commonly occurs secondary to blunt or penetrating ocular trauma, and intraocular surgical procedures, in which ocular contusion is the most common cause. [1, 2] It was reported that the percentage of iridodialysis in blunt injury was $9.3 \%$ [3], while that occurred in $0.2 \%$ of patients who underwent cataract surgeries. [4] Surgical repair should be carried out only if iridodialysis is associated with symptoms, such as monocular diplopia, photophobia, glare, accompanying with problems that unable to perform additional

\footnotetext{
* Correspondence: 173456764@qq.com

'Chongqing Key Laboratory of Ophthalmology and Chongqing Eye Institute, The First Affiliated Hospital of Chongqing Medical University, Chongqing 400016, People's Republic of China

Full list of author information is available at the end of the article
}

maneuvers in the iris or cosmetic deformations (e.g., polycoria and ectopic pupil).

Various surgical techniques have been used to restore the anatomy of iris, including closed [5-7] and open chamber [8] iridoplasty. Since the restored iris root was attached inside of the sclera incision in open chamber iridoplasty, reconstruction of closed chamber iris was proved to be safer and less invasive than open chamber techniques. [9] 26-gauge needle guided 10-0 nylon suture and double-armed polypropylene suture were two common techniques for closed chamber iridoplasty. [10-12] However, which technique offers better clinical remains unknown. Therefore, we here attempted to compare these two surgical techniques to determine their safety and effectiveness in treating iridodialysis.

(c) The Author(s). 2018 Open Access This article is distributed under the terms of the Creative Commons Attribution 4.0 International License (http://creativecommons.org/licenses/by/4.0/), which permits unrestricted use, distribution, and reproduction in any medium, provided you give appropriate credit to the original author(s) and the source, provide a link to the Creative Commons license, and indicate if changes were made. The Creative Commons Public Domain Dedication waiver (http://creativecommons.org/publicdomain/zero/1.0/) applies to the data made available in this article, unless otherwise stated. 


\section{Methods}

A retrospective cohort study was performed on the Department of Ophthalmology, First Affiliated Hospital of Chongqing Medical University (Chongqing, China). 75 patients with iridodialysis who underwent surgery from February 2008 to October 2017 were included in this study. Inclusion criteria were as follows: (1) The range of iridodialysis was more than 90 degrees; (2) Patients complained about monocular diplopia, photophobia, or glare; (3) Patients were unable to perform additional maneuvers in the iris; (4) Cosmetic problems (e.g., polycoria and ectopic pupil) were present. The study was approved by the Institutional Review Board, First Affiliated Hospital, Chongqing Medical University.

Age, gender, diagnosis, and treatment were recorded in the hospital's database. The following were thoroughly asseses in each patient before surgery and after surgery (1, 3 and 6 months): best corrected visual acuity (BCVA, that was monocularly assessed and recorded as LogMAR scores by using the standard logarithmic visual acuity chart), intraocular pressure (IOP), slit-lamp examination of the anterior and posterior segment, and complications. Postoperative gonioscopy was used to identify whether the iris root was reattached or anterior peripheral synechiae occurred. Minimal clinically important improvement (MCII) was defined as an improvement of more than 2 lines on the visual acuity chart. Corneal endothelium cell was counted to analyze the rate of endothelial cell loss.

These two closed-chamber iridodialysis repair procedures are both standard procedures in our hospital. Patients provided informed consent and chose the techniques. Patients were divided into two Groups according to different surgical techniques. In Group A, a 10-0 polypropylene suture was threaded through a 26-gauge needle, while in Group B, patients underwent double-armed polypropylene suture. [11] In Group A, a partial-thickness scleral tunnel was created $1.5 \mathrm{~mm}$ from the limbus along the extent of the iridodialysis. A 26-gauge needle threaded with 10-0 nylon suture was inserted into the anterior chamber through the limbus (180 degrees far from the iridodialysis), then pushed forward to engage the disinserted iris root and brought it out of the eye within the scleral bed. The free end of the suture was pulled out, and the needle was withdrawn into the anterior chamber with the suture remaining in the lumen of the needle. The procedure was repeated at another point, and the suture was pulled out to form a loop. These steps were repeated multiple times depending on the size of the iridodialysis until multiple loops laid over the scleral, approximately 2 sutures every quarter. The suture was cut,

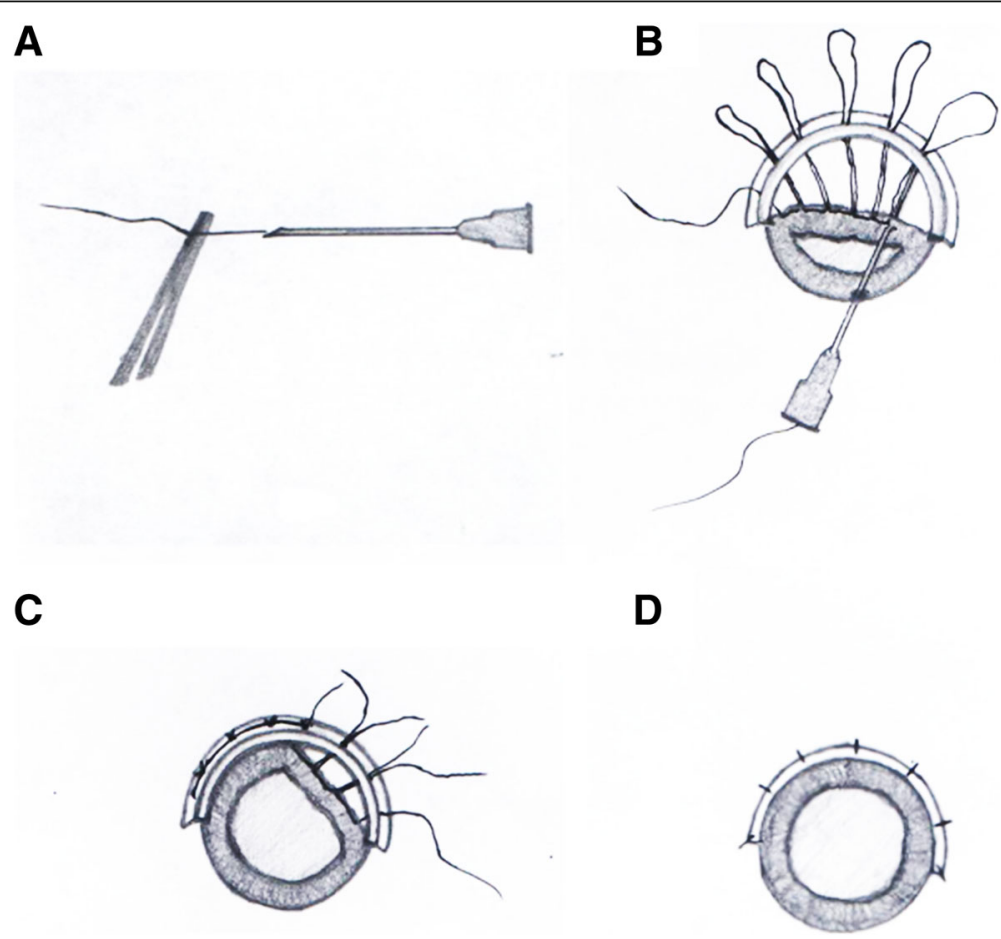

Fig. 1 Procedure using a 26-gauge hypodermic needle guided 10-0 nylon suture for iridodialysis repair. a: a 26-gauge needle was threaded with a 10-0 nylon suture. $\mathbf{b}$ : the needle with suture was inserted in the anterior chamber through the limbus, then pushed forward to engage the disinserted iris root, then brought it out through the scleral bed, the free end of the suture was pulled out, and the needle was retracted into the anterior chamber. The procedure was repeated at another point, and the suture was pulled out to form a loop. c: the loop of a suture was cut, and the ends were tied to pull the iris back. $\mathbf{d}$ : the partial-thickness scleral flap was sutured 
the ends were tied, the partial-thickness scleral flap was sutured, and the conjunctival peritomy was closed (Fig. 1). In Group B, a paracentesis was created on the opposite side of the cornea. One end of a double-armed 10-0 polypropylene suture on a curved needle was introduced into the anterior chamber via the paracentesis. The needle was driven through the iris base and penetrated out through the sclera $1 \mathrm{~mm}$ posterior to the limbus. After that, the second arm was introduced into the anterior chamber by the same paracentesis and passed through the second point of the iris base. The suture was tied at the paracentesis side, and the knot was pulled out through one of the sclera tunnels without scleral flap, to ensure scleral fixation. The procedure was repeated until the iris was restored [12] (Fig. 2). All the surgeries were performed under the same viscoelastic material (Medical sodium hyaluronate gel for ophthalmology, purchased from Shenyang Sinqi Pharmaceutical Co., Ltd., China) to maintain the stability of the anterior chamber.

\section{Statistical analysis}

Data analysis was performed using SPSS 16.0 software (SPSS Inc., Chicago, IL, USA). Results were expressed as the mean \pm standard deviation (SD). The independentsamples $t$-test was used to compare the variables. The paired sample $t$-test was used to compare the paired variables. Categorical variables were analyzed using two-tailed Pearson's chi-squared test. $P$-value $<0.05$ was considered statistically significant.

\section{Results}

\section{General information}

A total of 75 iridodialysis patients (75 eyes) were admitted to our ophthalmology department during the study period. 35 and 40 patients were assigned to Group A and Group B, respectively. However, 3 cases in Group A and 5 cases in Group B were excluded because the follow-up period was less than 6 months. Eventually, 32 and 35 patients were included in Group A and Group B, respectively (Table 1 ). In Group $A$, there were 30 males and 2 females, with ages of $32.3 \pm 11.0$ years. In Group B, there were 33 males and 2 females, with ages of $30.3 \pm$ 11.2 years. Neither the gender nor age was different between these two groups. All of the investigated patients were followed up for 6 to 96 months, with a mean follow-up duration of $27.8 \pm 12.3$ months.

Contusion was found to be the major cause of iridodialysis. A total of 37 eyes (20 eyes in Group A and 17 eyes in Group B) were accompanied with complicated cataract and/or lens subluxation that led to a remarkable visual impairment, therefore lens removal was performed with iridodialysis repair. 13 eyes (6 eyes in Group A and 7 eyes in Group B) underwent anterior vitrectomy because vitreous prolapsed into the anterior chamber with lens dislocation. The demographic data such as gender, age, causes of the disease, the degree of iridodialysis and number of cases accompanied with lens dislocation and anterior vitrectomy were not significantly different between Group A and Group B (Table 1).

\section{Efficiency of the two techniques for repairing iridodialysis repair}

The pupil shape restored to round or nearly round in all cases at 1,3, and 6 months after the operation. Gonioscopy showed that the iris root was reattached. The pupil shape was adjusted by a slit-lamp examination. In Group A, pupil shape recovered to round shape in 15 eyes (46.9\%), and nearly round shape in 17 eyes (53.1\%), as shown in Fig. 3. While in Group B, pupil shape recovered to round shape in 14 eyes $(40.0 \%)$, and nearly round shape in 21 eyes $(60.0 \%)$, as illustrated in Fig. 4. There were no significant differences
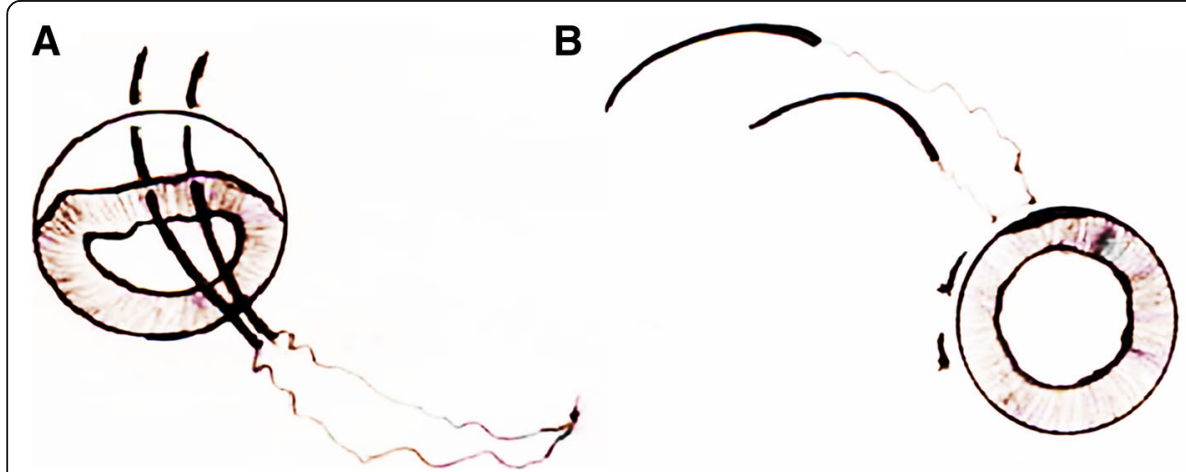

C

Fig. 2 Procedure using a double-armed polypropylene suture for iridodialysis repair. a: one end of a double-armed 10-0 polypropylene suture on a curved needle was introduced into the anterior chamber via a paracentesis. The needle was driven through the iris base and penetrated out through the sclera $(1 \mathrm{~mm})$, which was posterior to the limbus. Then, the second arm was introduced into the anterior chamber via the same paracentesis and passed through the second point of the iris base. The suture was tied at the paracentesis side. $\mathbf{b}$ : the knot was pulled out through one of the sclera tunnels without scleral flap. The iris was pulled back, while polypropylene suture was fixed on the scleral by the iridodialysis side. c: the knots were rotated within the scleral needle tract, and the procedure was repeated until the iris was restored 
Table 1 Demographic data of study subjects

\begin{tabular}{lllll}
\hline & Group A & Group B & $P$-value & Total \\
\hline Patients (N) & 32 & 35 & N/A & 67 \\
Eyes studied (n) & 32 & 35 & N/A & 67 \\
Gender (Male/Female) & $30 / 2$ & $33 / 2$ & 0.658 & $63 / 4$ \\
Age (years) & $32.3 \pm 11.0$ & $30.3 \pm 11.2$ & 0.479 & \\
$\begin{array}{l}\text { Causes } \\
\quad \text { Contusion (n) }\end{array}$ & 31 & 34 & 0.731 & 65 \\
$\quad$ Open globe(n) & 1 & 1 & & 2 \\
$\begin{array}{l}\text { Degree of iridodialysis } \\
\quad<1 \text { quadrant(n) }\end{array}$ & 11 & 9 & & \\
$\begin{array}{l}\text { 1-2 quadrant(n) } \\
>2 \text { quadrant(n) }\end{array}$ & 12 & 15 & 0.821 & 20 \\
$\begin{array}{l}\text { Surgical procedure } \\
\begin{array}{l}\text { Combined with } \\
\text { lens removal (n) }\end{array}\end{array}$ & 20 & 11 & & 27 \\
$\begin{array}{l}\text { Combined with } \\
\text { anterior vitrectomy } \\
\text { and lens removal(n) }\end{array}$ & 6 & 17 & 0.455 & 37 \\
\hline
\end{tabular}

between two Groups in terms of the reconstruction of pupil shape $\left(x^{2}=0.322, P=0.627\right)$.

A higher percentage of iris tear was found in Group A (9 eyes, $24.1 \%)$ compared to Group B ( 0 eyes) $\left(\chi^{2}=11.371\right.$, $P=0.001)$. Minor iris tear around the access passage to needle was detected in Group A, especially when the range of iridodialysis was wide (in 6 cases the degree of iridodialysis was higher than 2 quadrants), and/or with mild iris atrophy (2 cases). Hyphema caused by iris trauma was not observed as well. However, iris tear was not observed in Group B.

Limitation of vision acuity was not closely associated with iridodialysis. Improvement of visual function was found in 24 eyes (78.1\%) in Group A and 26 eyes (74.3\%) in Group $B$ at 1 month after the operation, without significant differences between the two Groups $(\chi 2=0.005, P=0.585)$. After 6 months of follow-up, visual function was eventually improved in all patients except for 2 eyes (optic atrophy and vitreous opacity) in Group A and 1 eye (a choroidal rupture) in Group B. Improvement of visual function not only was achieved by restoring the iris anatomy. Cataract and lens dislocation were also effectively treated.

\section{Safety of the two techniques for repairing iridodialysis}

IOP became normal at 1,3 , and 6 months after the operation, except 2 eyes (6.3\%) eyes in Group A and 3 eyes $(8.6 \%)$ eyes in Group B complicated with angle recession. There was no significant difference between these two Groups $\left(\chi^{2}=0.130, P=0.543\right)$. The rate of endothelial cell loss before and after the operation was not significantly different between Group A and Group B (Table 2).

The percentage of complicated cataract was not significantly different between Group A (2 eyes, 6.3\%) and Group B ( 2 eyes, 5.7\%) $(\chi 2=0.009, P=0.658)$. Besides, cataract surgery was not performed, as the lens opacity was not severe enough to greatly affect visual acuity. Hyphema was observed in 5 eyes (15.6\%) in Group A, and 1 eye $(5.9 \%)$ in Group B without observing significant differences between these two Groups $\left(\chi^{2}=3.342\right.$, $P=0.096$ ). Hyphema was absorbed 7 days after surgery without complications. No other complications were found during the follow-up period as well.

\section{Discussion}

The iris root is one of the weakest parts of iris that could be easily impaired. $[12,13]$ In the present study, contusion is the most common cause of iridodialysis. Two closed chamber techniques for iridodialysis repair have been shown to be safe and effective, although minor iris tear may be caused by a $10-0$ polypropylene suture that was threaded through a 26-gauge needle.

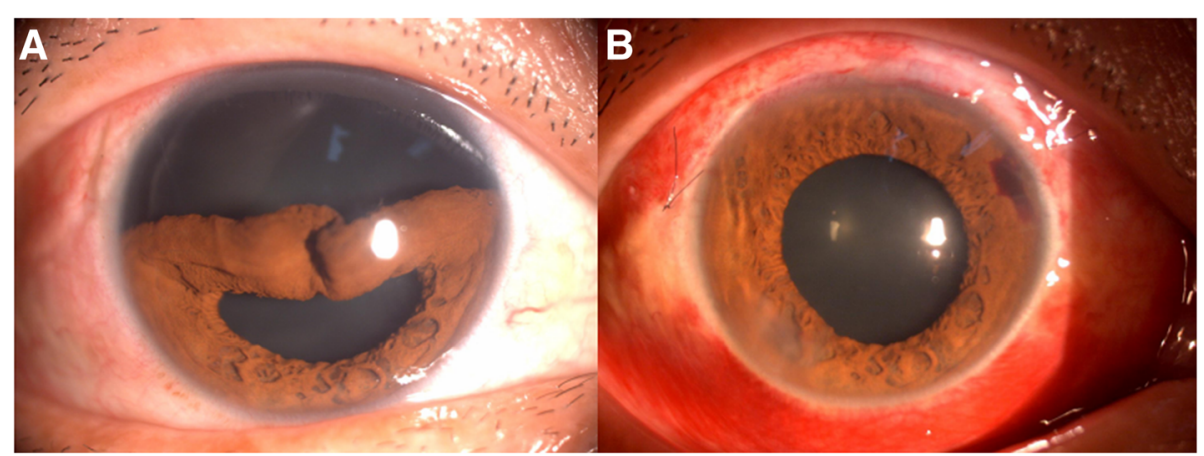

Fig. 3 Preoperative and postoperative slit-lamp photographs of iridodialysis patients who underwent 26-gauge hypodermic needle guided 10-0 nylon suture. a: preoperative appearance with iris dislocated between 9 o'clock to 3 o'clock, and the pupil shape became crescent. b: illustration of pupil restored to nearly round shape at 1 day after operation 


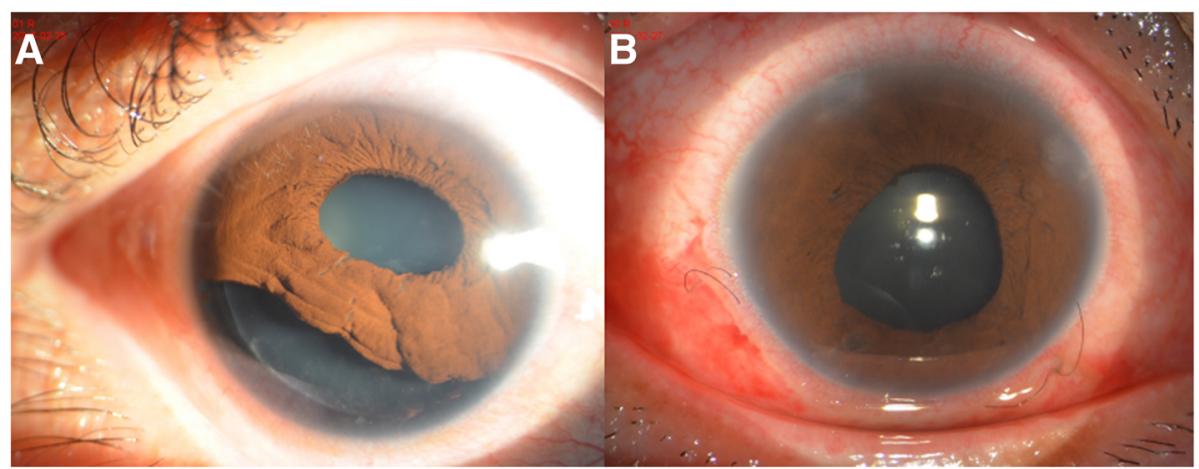

Fig. 4 Preoperative and postoperative slit-lamp photographs of iridodialysis patients who underwent double-armed polypropylene suture. a preoperative appearance with iris dislocated between 4 to 9 o'clock. b: illustration of pupil restored to nearly round shape at 1 day after operation

Different techniques including open-chamber $[8,9]$ and closed-chamber [11, 12] approaches for surgical repair of traumatic iridodialysis have been reported. After Paton presented an incarceration technique in 1973 [8], McCannel [9] introduced a surgical method that uses a curved needle and a 10-0 nylon suture. Both methods were open-chamber techniques. As the iris was squeezed between the sclera lips, open-chamber technique is not precise in restoring the anatomy of iris, and may increase the risk of infection, [6] and in some rare cases, cause epithelialization of the anterior chamber . [13] A number of closed-chamber technique has been reported as well. For instance, Nunziata [11] used a $17.0 \mathrm{~mm}$ straight needle and a 10-0 polypropylene suture. However, the $17.0 \mathrm{~mm}$ straight needle did not have a handle, thus manipulation is difficult and the needle may easily damage the crystalline lens. A curved needle would potentially avoid the above mentioned problems. Bardak [6] used a $22.0 \mathrm{~mm} 26$-gauge straight needle with a hole $(1.0 \mathrm{~mm})$ from the tip to insert a $10-0$ suture which was similar to ours, however, scleral flap might decrease the risk of delayed-onset intraocular infection including endophthalmitis. [14] In addition to these techniques, 'hang back' surgical approach was proposed to titrate the tightness of anchoring of the suture [15] in order to facilitate manipulation by using a 27 gauge needle [12]. Knotless technique [16] and single-tread single-knot suture [5] are two other techniques. Two approaches were chosen in our study: 1) 26-gauge straight needle guided suture with scleral flap, and 2) double-armed 10-0 polypropylene suture. Both approaches were proved safe and effective methods during a 6-month follow-up period.

Minor iris tear around the area where the needle passes through was observed in certain patients who underwent 26-gauge needle guided suture, but not in those treated with a double-armed polypropylene suture with a curved needle. The outer diameter of a 26-gauge hypodermic needle was $0.45 \mathrm{~mm}$, while the cross-section of the double-armed curved needle was $0.2 \times 0.1 \mathrm{~mm}^{2}$. The puncture area on the iris made by a 26-gauge needle was larger than that created by a double-armed curved needle. Thus, weaker or atrophic peripheral iris might be more likely to be avulsed by a 26-gauge needle. Bhende [7] used a 30-gauge hypodermic needle (outer diameter $=0.3 \mathrm{~mm}$ ), which might be less invasive than a 26-gauge needle, however, the cross-section area was still larger than that of double-armed curved needle. Complications such as hyphema was not observed, and the pupil shape and visual function were not affected either.

There are several limitations in our study: it is a retrospective study, and the sample size was small as well. The minimum or maximum mesopic size of pupil was not recorded by objective anterior eye segment analysis system, such as corneal topography or anterior eye segment tomography. Subjective

Table 2 Comparing mean corneal endothelium cell count and the corresponding loss rate between group A and group B before and after the operation

\begin{tabular}{|c|c|c|c|c|}
\hline $\begin{array}{l}\text { Mean Corneal Endothelium Cell } \\
\text { Count and loss rate }\left(/ \mathrm{mm}^{2}, \%\right)\end{array}$ & Pre-operation & 1 month after operation & 3 months after operation & 6 months after operation \\
\hline Group A & $2479.3 \pm 226.5$ & $2122.6 \pm 186.7,14.4$ & $2273.8 \pm 211.4,8.3$ & $2347.4 \pm 219.2,5.3$ \\
\hline Group B & $2386.8 \pm 235.2$ & $2117.4 \pm 205.1,11.3$ & $2196.2 \pm 202.8,8.0$ & $2232.9 \pm 207.7,6.5$ \\
\hline P-value & & 0.262 & 0.577 & 0.582 \\
\hline
\end{tabular}


discomfort including glare pre- and post- operation that might be relevant to the extent of dialysis was not analyzed in the study. A longer duration of follow-up, objective analyses of post-operative pupil size, as well as subjective evaluation should be considered in the future prospective studies.

\section{Conclusions}

Our study compared two closed-chamber approaches for iridodialysis repair. The results revealed that both methods were safe and effective in correcting the functional and cosmetic problems.

\section{Abbreviations}

BCVA: Best corrected visual acuity; BCVA: Intraocular pressure; MCII: Minimal clinically important improvement

\section{Acknowledgments}

The authors would like to thank Prof. Xiaoxin Luke Chen, M.D. PhD, North Carolina Central University, NC US and Junyan Zhang from Bothwin Clinical Study Consultant, WA, USA for for English editing and suggestion on this trial.

\section{Availability of data and material}

The datasets used and/or analyzed during the current study are available from the corresponding author upon reasonable request.

\section{Funding}

This study was supported by the National Natural Science Foundation of China (Grant No. 81300794), and National Key Clinical Specialties Construction Program of China. The sponsors had no role in the design and conduct of the study; collection, analysis, and interpretation of the data; preparation, review, or approval of the manuscript; and decision to submit the manuscript for publication.

\section{Authors' contributions}

$C L$ and WJW designed the study and analyzed the data. WJW and LS collected, analyzed and interpreted the data. CL and WJW drafted and revised the manuscript. All authors read and approved the final manuscript.

\section{Ethics approval and consent to participate}

The study was approved by the Institutional Review Board of the First Affiliated Hospital of Chongqing Medical University, and all patients provided their informed consent before starting the treatment. As it was a retrospective clinical study, all the patients were contacted by telephone to obtain verbal informed consent and it was approved by the ethics committee.

\section{Consent for publication}

Not applicable.

\section{Competing interests}

The authors declare that they have no competing interests.

\section{Publisher's Note}

Springer Nature remains neutral with regard to jurisdictional claims in published maps and institutional affiliations.

\section{Author details}

'Chongqing Key Laboratory of Ophthalmology and Chongqing Eye Institute, The First Affiliated Hospital of Chongqing Medical University, Chongqing 400016, People's Republic of China. ${ }^{2}$ The Fifth Affiliated Hospital of Zhengzhou University, Zhengzhou 450052, People's Republic of China.
Received: 17 July 2018 Accepted: 29 November 2018

Published online: 07 December 2018

\section{References}

1. Viestenz A, Kuchle M. Ocular contusion caused by elastic cords: a retrospective analysis using the Erlangen ocular contusion registry. Clin Exp Ophthalmol. 2002:30:266-9.

2. Bang $\mathrm{SP}$, Jun JH. Iris reconstruction using autologous iris preserved in cold balanced salt solution for 8 hours in iatrogenic total iridodialysis during cataract surgery: a case report. BMC Ophthalmol. 2017;17:39.

3. Ulagantheran V, Ahmad Fauzi MS, Reddy SC. Hyphema due to blunt injury: a review of 118 patients. Int J Ophthalmol. 2010;3:272-6.

4. Sangameswaran RP, Verma GK, Raghavan N, Joseph J, Sivaprakasam M. Cataract surgery in mobile eye surgical unit: safe and viable alternative. Indian J Ophthalmol. 2016:64:835-9.

5. Silva JL, Povoa J, Lobo C, Murta J. New technique for iridodialysis correction: single-knot sewing-machine suture. J Cataract Refract Surg. 2016:42:520-3.

6. Bardak Y, Ozerturk Y, Durmus M, Mensiz E, Aytuluner E. Closed chamber iridodialysis repair using a needle with a distal hole. J Cataract Refract Surg. 2000:26:173-6

7. Bhende P. Closed chamber iridodialysis repair using a needle with a distal hole. J Cataract Refract Surg. 2000;26:1267-8.

8. Paton D. Management of iridodialysis. Ophthalmic Surg Ophthalmic Surg. 4:38-9.

9. McCannel MA. A retrievable suture idea for anterior uveal problems. Ophthalmic Surg. 1976;7:98-103.

10. Khokhar S, Gupta S, Kumar G. Iridodialysis repair: stroke and dock technique. Int Ophthalmol. 2014;34:331-5.

11. Nunziata BR. Repair of iridodialysis using a 17-millimeter straight needle. Ophthalmic Surg. 1993;24:627-9.

12. Wachler BB, Krueger RR. Double-armed McCannell suture for repair of traumatic iridodialysis. Am J Ophthalmol. 1996;122:109-10.

13. Abbott RL, Spencer WH. Epithelialization of the anterior chamber after transcorneal (McCannel) suture. Arch Ophthalmol. 1978;96:482-4.

14. Heilskov T, Joondeph BC, Olsen KR, Blankenship GW. Late endophthalmitis after transscleral fixation of a posterior chamber intraocular lens. Arch Ophthalmol. 1989:107:1427.

15. Snyder ME, Lindsell LB. Nonappositional repair of iridodialysis. J Cataract Refract Surg. 2011:37:625-8.

16. Voykov B. Knotless technique for iridodialysis repair. Clin Exp Ophthalmol. 2016:44:135-6.

Ready to submit your research? Choose BMC and benefit from:

- fast, convenient online submission

- thorough peer review by experienced researchers in your field

- rapid publication on acceptance

- support for research data, including large and complex data types

- gold Open Access which fosters wider collaboration and increased citations

- maximum visibility for your research: over $100 \mathrm{M}$ website views per year

At BMC, research is always in progress.

Learn more biomedcentral.com/submissions 